\section{(6) OPEN ACCESS}

\title{
Taking up physical activity in later life and healthy ageing: the English longitudinal study of ageing
}

\author{
Mark Hamer, ${ }^{1}$ Kim L Lavoie, ${ }^{2,3}$ Simon L Bacon ${ }^{2,4,5}$
}

\begin{abstract}
- Online supplementary tables S1 and S2 are published online only. To view these files please visit the journal online (http:// dx.doi.org/10.1136/bjsports2013-092993).
\end{abstract}

${ }^{1}$ Physical Activity Research Group, Department of Epidemiology and Public Health, University College London, London, UK

${ }^{2}$ Montreal Behavioural Medicine Centre, Hôpital du Sacré-Coeur de Montréal, A University of Montreal Affiliated Hospital, Montréal, Quebec, Canada

${ }^{3}$ Department of Psychology, University of Quebec at Montreal (UQAM), Montreal, Quebec, Canada

${ }^{4}$ Research Center, Montreal Heart Institute, Concordia University, Montreal, Quebec, Canada

${ }^{5}$ Department of Exercise Science, Concordia University, Montreal, Quebec, Canada

\section{Correspondence to} Dr Mark Hamer, Department of Epidemiology and Public Health, 1-19 Torrington Place, University College London, London WC1E 6BT, UK; m.hamer@ucl.ac.uk

Received 15 August 2013 Revised 16 September 2013 Accepted 24 September 2013 Published Online First 25 November 2013



\footnotetext{
To cite: Hamer M Lavoie KL, Bacon SL. Br J Sports Med 2014:48: 239-243.
}

\section{ABSTRACT}

Background Physical activity is associated with improved overall health in those people who survive to older ages, otherwise conceptualised as healthy ageing. Previous studies have examined the effects of mid-life physical activity on healthy ageing, but not the effects of taking up activity later in life. We examined the association between physical activity and healthy ageing over 8 years of follow-up.

Methods Participants were 3454 initially disease-free men and women (aged 63.7 \pm 8.9 years at baseline) from the English Longitudinal Study of Ageing, a prospective study of community dwelling older adults. Self-reported physical activity was assessed at baseline (2002-2003) and through follow-up. Healthy ageing, assessed at 8 years of follow-up (2010-2011), was defined as those participants who survived without developing major chronic disease, depressive symptoms, physical or cognitive impairment.

Results At follow-up, 19.3\% of the sample was defined as healthy ageing. In comparison with inactive participants, moderate $(\mathrm{OR}, 2.67,95 \% \mathrm{Cl} 1.95$ to 3.64$)$, or vigorous activity $(3.53,2.54$ to 4.89$)$ at least once a week was associated with healthy ageing, after adjustment for age, sex, smoking, alcohol, marital status and wealth. Becoming active (multivariate adjusted, $3.37,1.67$ to 6.78$)$ or remaining active $(7.68,4.18$ to 14.09 ) was associated with healthy ageing in comparison with remaining inactive over follow-up. Conclusions Sustained physical activity in older age is associated with improved overall health. Significant health benefits were even seen among participants who became physically active relatively late in life.

\section{INTRODUCTION}

In a growing elderly population, healthy ageing is becoming a crucial factor to reduce the burden of disease and disability and related healthcare costs. ${ }^{1}$ One of the key targets recently outlined by the European Commission's Active and Healthy Ageing Innovation Partnership is to achieve an increased healthy life expectancy of 2 years by the year $2020 .^{2}$ Healthy ageing is a multidimensional phenotype and does not merely capture the absence of clinical disease, but also incorporates freedom from physical disability, plus preserved cognitive, affective and social functioning. ${ }^{3}$ There are limited data on modifiable midlife risk factors for healthy ageing. Emerging evidence suggests that regular physical activity is among the most important lifestyle factors for maintenance of good health at older ages. Across developed regions of the world, inactivity ranks alongside tobacco, alcohol and obesity as a leading cause of reduced healthy life expectancy. ${ }^{4}$ Inactivity contributes to several specific health and function problems in old age, and has pronounced effects on strength, flexibility, aerobic capacity, walking capacity, balance and mental and cognitive decline. ${ }^{56}$ For example, randomised controlled trials in elderly samples have demonstrated favourable effects of exercise training on cognitive ${ }^{7}$ and physical function. ${ }^{8}$ In addition, physical activity has been associated with increased survival in the elderly. ${ }^{9}{ }^{10}$

Several epidemiological studies have previously examined the prospective association between mid-life physical activity and healthy ageing using a multidimensional construct made up of components including chronic disease, mental health, physical and cognitive function. ${ }^{11-15}$ The Cardiovascular Health Study ${ }^{13}$ the Harvard alumni study ${ }^{14}$ Whitehall II study ${ }^{12}$ and Nurses' Health Study ${ }^{11}$ all observed robust associations between physical activity and exceptional survival. However, one of the limitations of prior studies is a failure to capture the effects of changes in physical activity through follow-up. A major advantage of using data from cohort studies with repeated assessments is the ability to examine the effects of changes in physical activity on health outcomes. This issue is particularly relevant in older populations as there is limited evidence on the health effects of becoming physically active relatively late in life.

The aim of this study was to examine the association between physical activity and healthy ageing over an 8-year follow-up in the English Longitudinal Study of Ageing (ELSA). We specifically focused on the effects of physical activity changes through follow-up on healthy ageing.

\section{MATERIALS AND METHODS}

Study sample and procedures

ELSA is an ongoing cohort study that contains a nationally representative sample of the English population living in households. ${ }^{16}$ The ELSA cohort consists of men and women born on or before 29 February 1952. The sample was drawn from households that have participated in Health Survey for England (HSE) in 1998, 1999 and 2001 ('wave 0'). HSE recruits participants using multistage-stratified probability sampling with postcode sectors selected at the first stage and household addresses selected at the second stage. Interviews at baseline (wave 1; 2002-2003) were carried out with 11391 individuals (5186 men and 6205 women); the overall response rate was $70 \%$ at the household level and $67 \%$ at the individual level. Participants were re-assessed every 2 years thereafter and follow-up for healthy ageing was made 8 years later at wave 5 (2010-2011). The present analysis contained survivors at follow-up. 
Participants gave full informed written consent to participate in the study and ethical approval was obtained from the London Multi-Centre Research Ethics Committee.

\section{Physical activity assessment}

Self-reported physical activity was collected at baseline, and included questions on the frequency of participation in vigorous, moderate and light physical activities (more than once per week, once per week, one to three times per month, hardly ever). Physical activity was further categorised into three groups, as previously described ${ }^{17}$ : inactive (no moderate or vigorous activity on a weekly basis); moderate activity at least once a week and vigorous activity at least once a week. These physical activity questions were repeated at wave 3 (2006-2007), thus enabling us to assess changes in physical activity levels through follow-up. A binary physical activity variable (inactive or moderate/vigorous activity) was created and a change in physical activity over 4 years (waves 1-3) was categorised into four groups: always inactive, became inactive, became active and always active. We have recently validated the physical activity questionnaire in 116 (61 men and 55 women) ELSA participants (aged 64.5 \pm 12.5 years) using objective accelerometry devices (Hamer $M$, 2012; unpublished data). Participants wore a GeneActiv device on their wrist for seven consecutive days. The three category exposure variable described above was moderately correlated with objectively assessed hours per day of moderate-vigorous intensity activity (Spearman's $\mathrm{r}=0.21, \mathrm{p}=0.02$ ).

\section{Outcome: healthy ageing}

Although there is no consensus on the definition of healthy ageing, recent working definitions have included not only disease status but also cognitive, physical and other functions. For the current analyses we employed previously described criteria $^{11} 12$ for the following four domains: (1) being free from major chronic disease; (2) having no major impairment of cognitive function; (3) having no major limitation of physical functions and (4) and having good mental health. Healthy ageing was defined as those participants who survived without developing any of the above limitations.

Disease status was measured using self-reported physician diagnosis of major chronic diseases, including cardiovascular diseases (arrhythmia, myocardial infarction, congestive heart failure, angina, heart murmur, stroke) diabetes or high blood sugar, cancer, obstructive lung diseases (including chronic bronchitis, emphysema), Parkinson's disease or Alzheimer disease.

Cognitive function was assessed objectively using a battery of widely used neuropsychological tests validated through clinicalpathological studies. ${ }^{18}$ Participants were presented with a list of 10 words that were read out by a computer at the rate of one word every $2 \mathrm{~s}$. A total of four such lists were available and these were randomly allocated by the computer. Following presentation of the words, participants were asked to recall as many words as they could (immediate recall). Participants were also asked to recall these words after an interval during which they completed other cognitive function tests (delayed recall). The number of correctly recalled words was used as a measure of memory. Verbal fluency was used as a measure of executive function. Participants were asked to name as many members of a specific category (in this case, animals) as they could in $1 \mathrm{~min}$. The number of animals named was used as a measure of executive function. A global cognitive function score was calculated from the sum of standardised scores on each test, as previously described. ${ }^{12}$ A global score of less than -1 SD from the mean was used to define cognitive impairment.

\section{Mental health}

Depressive symptoms were assessed using the eight-item Centre of Epidemiological Studies Depression (CES-D) scale. As in previous studies, we used a score of $\geq 4$ to define cases of elevated depressive symptoms. ${ }^{19}$ The CES-D is highly validated for use in older adults and displays excellent psychometric properties. ${ }^{20} 21$

\section{Disability and physical function}

We assessed disability based on participants' responses to questions on perceived difficulties in basic (eg, difficulty dressing, including putting on shoes and socks) ${ }^{22}$ and instrumental (eg, difficulty preparing a hot meal) activities of daily living. ${ }^{23}$ Participants with difficulties in one or more activities were considered to have some degree of disability. Physical functioning was objectively assessed using walking speed measured over an 8 -foot long $(2.44 \mathrm{~m})$ course. Adequate physical function was defined as gait speed greater than $0.6 \mathrm{~m} / \mathrm{s}$, which has previously been used as a cut-point to predict poor health and function. ${ }^{24}$

\section{Covariates}

Baseline demographic and health-related covariates included cigarette smoking (current, previous or non-smoker), current frequency of alcohol intake (daily, at least weekly, rarely, never), marital status (married, single, divorced, widowed). Wealth was used as our measure of socioeconomic status, as this has been shown to best capture the material resources available to older adults. ${ }^{25}$ Wealth was calculated as net of debt and included the total value of the participant's home (excluding mortgage), financial assets such as savings, business assets, and physical wealth such as artwork or jewellery.

\section{Statistical analyses}

We used $\chi^{2}$ tests to examine differences in baseline characteristics with respect to healthy ageing. Multiple logistic regressions were used to examine the association between physical activity at baseline and healthy ageing at follow-up. In multivariate models, we adjusted for several covariates in a step-wise fashion: model 1 contained basic variables including age and sex; model 2 contained additional baseline behavioural and demographic covariates, including smoking, alcohol use, marital status and wealth quintile. Covariates were selected a priori based on existing data linking these covariates to both physical activity and healthy ageing. ${ }^{11-15}$ We used a similar modelling approach to investigate associations between change in physical activity and healthy ageing. All analyses were conducted using SPSS V.20.

\section{RESULTS}

The selection of participants for the present study is summarised in figure 1. Any participants with existing chronic disease at baseline (wave 1) and wave 2 were excluded. The final analytic sample comprised 3454 individuals (aged 63.7 \pm 8.9 years at baseline, $42.5 \%$ men). Excluded participants were slightly older (64.4 vs 63.7 years, $\mathrm{p}=0.002$ ), more likely to be physically inactive $(27.7 \%$ vs $18.9 \%, \mathrm{p}<0.001)$, and less wealthy $(17.4 \%$ in top quintile vs $23.6 \%, \mathrm{p}<0.001)$ compared with those included. At baseline, participants who were defined as healthy agers at follow-up (19.3\% of the sample) were older, more likely to be never smokers, regular alcohol drinkers, more physically active, married and had greater wealth (table 1). In a subsample of participants $(\mathrm{N}=1953)$ with available clinical data from the wave 2 nurse assessment, healthy agers demonstrated more favourable lipid profiles and glycaemic control, lower 
Figure 1 A flow chart describing the selection of participants for the present study.

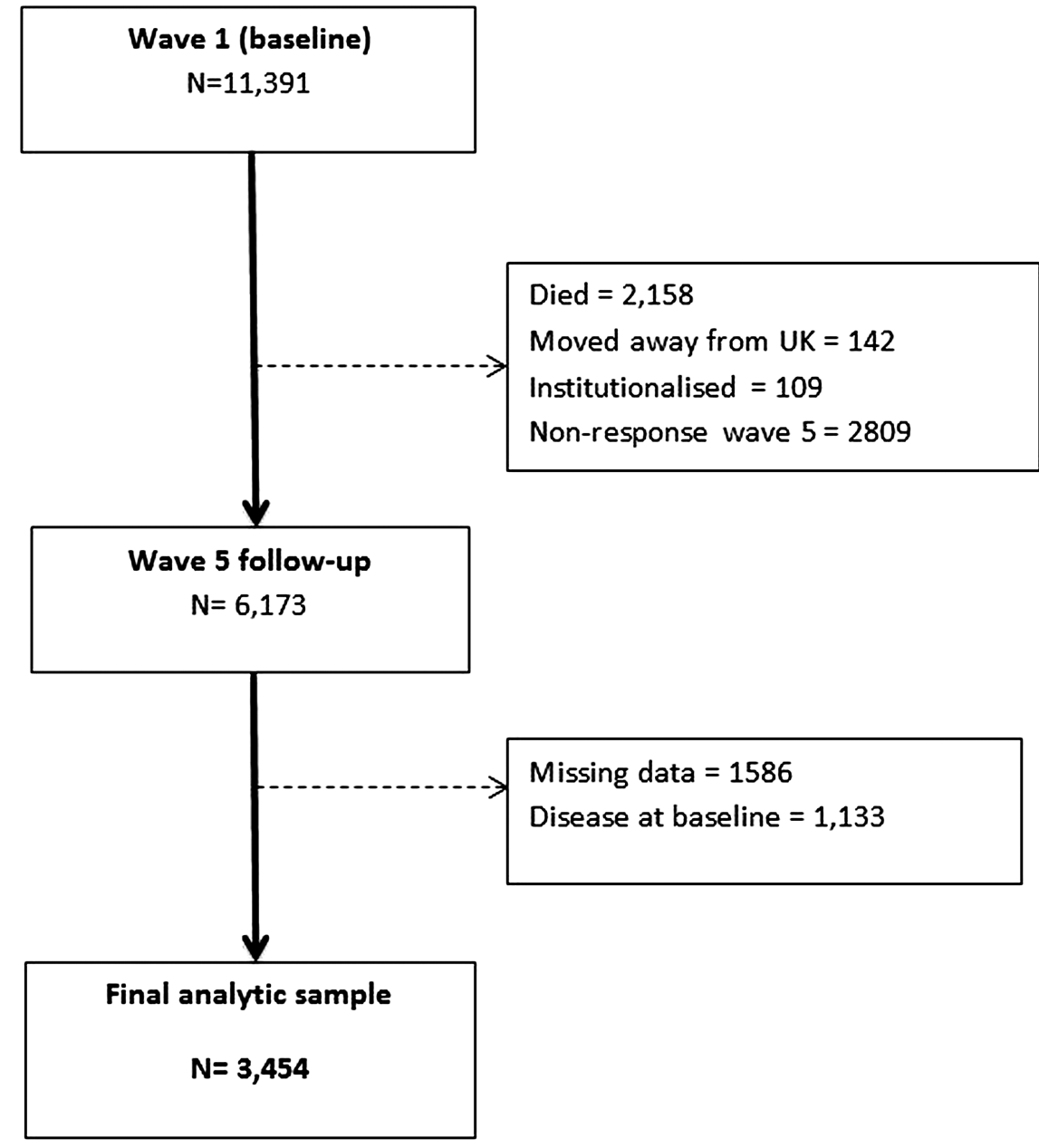

body mass index and higher blood haemoglobin levels (see online supplementary table S1).

\section{Baseline physical activity and healthy ageing at follow-up} At follow-up, $38.4 \%$ of the sample had developed a chronic illness, $17.6 \%$ reported depressive symptoms, $32 \%$ reported disability, $19.2 \%$ had cognitive impairment and $17.7 \%$ had inadequate gait speed. There was a dose-response association between baseline physical activity and healthy ageing at 8 years follow-up, such that participants reporting participation in moderate or vigorous activity were 3.1 -fold and 4.3 -fold more likely to be healthy agers, respectively, in comparison with inactive participants (table 2). These effect estimates were only slightly attenuated after adjustment for standard covariates and did not appear to be influenced by further adjustment for biological risk factors (see online supplementary table S2). Among the covariates, wealth and smoking predicted healthy ageing; compared with participants in the poorest quintile, those in the richest were more likely to be healthy agers (multivariate adjusted $\mathrm{OR}=2.81,95 \%$ CI 1.93 to 4.10 ). Smokers were less likely to be healthy agers (multivariate adjusted $\mathrm{OR}=0.66,0.48$ to 0.89 ). When we examined the association between physical activity and individual components of healthy ageing, all components remained independently associated with physical activity after mutual adjustment for one another (table 3 ).

\section{Change in physical activity and successful ageing}

We examined associations between 4-year change in physical activity and subsequent healthy ageing. Over the 4 years, $8.9 \%$ of the sample remained inactive, $11.9 \%$ became inactive, 9\% became active and $70.1 \%$ remained active (moderate or vigorous activity at least once a week). Becoming active or remaining active was associated with healthy ageing in comparison with remaining inactive (table 4), and these associations persisted in fully adjusted models.

\section{DISCUSSION}

The main findings from the present study demonstrate a doseresponse association between physical activity and healthy ageing over 8 years of follow-up in an initially disease-free population. The novel aspect of this study was in examining the impact of changes in physical activity on healthy ageing, made possible by repeated collection of physical activity data over follow-up. Importantly, we demonstrate, for the first time, that participants who remained physically active through follow-up were most likely to age successfully, although participants who took up activity during the follow-up period were also more likely to remain healthy compared with those who were inactive throughout. In fact, participants who remained active over 4 years of follow-up were over sevenfold more likely to be healthy agers after covariate adjustment. In comparison, when using a single assessment of physical activity at baseline, participants reporting vigorous activity were just over three times more likely to be healthy agers. Thus, repeated assessment of the exposure variable improved prediction of our outcome. Undoubtedly, controlled trials are the best test of causality. However, longitudinal studies of community samples have several advantages in that they are more representative, and can be followed up over longer periods of time without the risk of 
Table 1 Characteristics of the study population at baseline $(\mathrm{N}=3454)$

\begin{tabular}{|c|c|c|c|}
\hline & $\begin{array}{l}\text { Healthy } \\
\text { ageing } \\
(n=665)\end{array}$ & $\begin{array}{l}\text { Unhealthy } \\
\text { ageing }(n=2789)\end{array}$ & $p$ Value \\
\hline Age (years) & $67.0 \pm 4.2$ & $62.9 \pm 9.5$ & $<0.001$ \\
\hline Men & $300(45.1)$ & $1169(41.9)$ & 0.13 \\
\hline Smoking & & & $<0.001$ \\
\hline Never & 307 (46.2) & $1010(36.2)$ & \\
\hline Previous & $301(45.3)$ & $1264(45.3)$ & \\
\hline Current & $57(8.6)$ & $515(18.5)$ & \\
\hline Alcohol intake & & & 0.017 \\
\hline Daily & 217 (32.6) & $804(28.8)$ & \\
\hline $\begin{array}{l}\text { At least once per week } \\
\text { (but not daily) }\end{array}$ & $220(33.1)$ & 891 (31.9) & \\
\hline Rarely & $186(28.0)$ & $822(29.5)$ & \\
\hline Never & $42(6.3)$ & $272(9.8)$ & \\
\hline Physical activity & & & $<0.001$ \\
\hline Inactive & $55(8.3)$ & $598(21.4)$ & \\
\hline $\begin{array}{l}\text { Moderate (at least once } \\
\text { per week) }\end{array}$ & $345(51.9)$ & $1347(48.3)$ & \\
\hline $\begin{array}{l}\text { Vigorous (at least once } \\
\text { per week) }\end{array}$ & $265(39.8)$ & $844(30.3)$ & \\
\hline Marital status & & & 0.016 \\
\hline Married & $479(72.0)$ & $1890(67.8)$ & \\
\hline Single, never married & $25(3.8)$ & $141(5.1)$ & \\
\hline Separated/divorced & $56(8.4)$ & $341(12.2)$ & \\
\hline Widowed & $105(15.8)$ & $417(15.0)$ & \\
\hline Wealth quintile & & & $<0.001$ \\
\hline 1 (lowest) & $45(6.8)$ & $458(16.4)$ & \\
\hline 2 & $103(15.5)$ & $538(19.3)$ & \\
\hline 3 & $135(20.3)$ & $601(21.5)$ & \\
\hline 4 & $172(25.9)$ & $586(21.0)$ & \\
\hline 5 (highest) & $210(31.6)$ & 606 (21.7) & \\
\hline
\end{tabular}

Percentages denoted in brackets.

contamination effects that is a concern in trials with extended follow-up. In the present study we aimed to minimise possible confounding by controlling for key covariables (including age, sex, smoking, alcohol intake, marital status and wealth as a marker of social status) and reduce the risk of reverse causality by removing participants with prevalent disease at baseline. We also demonstrated associations between healthy ageing and several biomarkers that have been previously associated with physical activity in

Table 2 OR $(95 \% \mathrm{Cl})$ for the association of baseline physical activity and healthy ageing over 8 years follow-up ( $N=3454)$

\begin{tabular}{|c|c|c|c|}
\hline & $\begin{array}{l}\text { Healthy ageing } \\
\text { cases } \\
\text { Total } \mathrm{N}\end{array}$ & $\begin{array}{l}\text { Model } 1 \\
\text { OR }(95 \% \mathrm{Cl})\end{array}$ & $\begin{array}{l}\text { Model } 2 \\
\text { OR }(95 \% \mathrm{CI})\end{array}$ \\
\hline Inactive & $55 / 653$ & 1.00 (ref) & 1.00 \\
\hline $\begin{array}{l}\text { Moderate physical } \\
\text { activity }\end{array}$ & $345 / 1692$ & 3.12 (2.30 to 4.24$)$ & 2.67 (1.95 to 3.64$)$ \\
\hline $\begin{array}{l}\text { Vigorous physical } \\
\text { activity }\end{array}$ & $265 / 1109$ & 4.35 (3.16 to 5.98$)$ & 3.53 (2.54 to 4.89$)$ \\
\hline $\mathrm{p}$-trend & & $<0.001$ & $<0.001$ \\
\hline
\end{tabular}

Table 3 OR $(95 \% \mathrm{Cl})$ for the association of physical activity and different components of healthy ageing over 8 years follow-up $(\mathrm{N}=3454)$

\begin{tabular}{|c|c|c|}
\hline & $\begin{array}{l}\text { Model } 1 \\
\text { OR (95\% Cl) }\end{array}$ & $\begin{array}{l}\text { Model } 2 \\
\text { OR (95\% Cl) }\end{array}$ \\
\hline \multicolumn{3}{|l|}{ Chronic disease } \\
\hline Inactive & 1.00 (ref) & 1.00 \\
\hline Moderate physical activity & 0.70 (0.58 to 0.84$)$ & 0.78 (0.64 to 0.95$)$ \\
\hline Vigorous physical activity & 0.61 (0.50 to 0.74$)$ & 0.67 (0.54 to 0.84$)$ \\
\hline p-trend & $<0.001$ & 0.001 \\
\hline \multicolumn{3}{|l|}{ Depressive symptoms (CES-D>3) } \\
\hline Inactive & 1.00 (ref) & 1.00 \\
\hline Moderate physical activity & 0.51 (0.41 to 0.64$)$ & 0.67 (0.53 to 0.85$)$ \\
\hline Vigorous physical activity & $0.36(0.27$ to 0.46$)$ & 0.51 (0.39 to 0.67$)$ \\
\hline $\mathrm{p}$-trend & $<0.001$ & 0.001 \\
\hline \multicolumn{3}{|l|}{ Cognitive impairment } \\
\hline Inactive & 1.00 (ref) & 1.00 \\
\hline Moderate physical activity & $0.71(0.56$ to 0.90$)$ & 0.88 (0.69 to 1.13$)$ \\
\hline Vigorous physical activity & 0.49 (0.37 to 0.64$)$ & 0.64 (0.48 to 0.85$)$ \\
\hline $\mathrm{p}$-trend & $<0.001$ & 0.005 \\
\hline \multicolumn{3}{|l|}{ ADL/IADL } \\
\hline Inactive & 1.00 (ref) & 1.00 \\
\hline Moderate physical activity & $0.43(0.35$ to 0.52$)$ & 0.57 (0.46 to 0.70$)$ \\
\hline Vigorous physical activity & $0.30(0.24$ to 0.37$)$ & 0.41 (0.33 to 0.52$)$ \\
\hline $\mathrm{p}$-trend & $<0.001$ & $<0.001$ \\
\hline \multicolumn{3}{|l|}{ Impaired gait speed $(<0.6 \mathrm{~m} / \mathrm{s})$} \\
\hline Inactive & 1.00 (ref) & 1.00 \\
\hline Moderate physical activity & $0.38(0.30$ to 0.49$)$ & $0.54(0.40$ to 0.72$)$ \\
\hline Vigorous physical activity & $0.23(0.17$ to 0.32$)$ & 0.41 (0.29 to 0.58$)$ \\
\hline $\mathrm{p}$-trend & $<0.001$ & $<0.001$ \\
\hline
\end{tabular}

ELSA. ${ }^{17}$ This supports the biological plausibility of our findings and further reinforces the likelihood of causality. Thus, taken together prospective observational studies of representative community samples are an important approach for establishing links between physical activity and healthy ageing.

The prevalence of healthy ageing in ELSA is comparable with previous studies. For example, in the Nurses' Health Study, $10.8 \%$ met the criteria for healthy ageing ${ }^{11}$ and $20.9 \%$ met the

Table 4 OR $(95 \% \mathrm{Cl})$ for the association of physical activity change over wave $1-3$ and healthy ageing at follow-up $(\mathrm{N}=3051)$

\begin{tabular}{lrll}
\hline & $\begin{array}{l}\text { Healthy } \\
\text { ageing } \\
\text { cases } \\
\text { Total N }\end{array}$ & $\begin{array}{l}\text { Model 1 } \\
\text { OR (95\% Cl) }\end{array}$ & $\begin{array}{l}\text { Model 2 } \\
\text { OR (95\% Cl) }\end{array}$ \\
\hline Remained inactive & $12 / 273$ & 1.00 (ref) & 1.00 \\
Became inactive & $37 / 363$ & $2.50(1.27$ to 4.94$)$ & $2.36(1.19$ to 4.68$)$ \\
Became active & $34 / 275$ & $3.57(1.79$ to 7.14$)$ & $3.37(1.67$ to 6.78$)$ \\
Remained active & $521 / 2140$ & $9.51(5.22$ to 17.33$)$ & $7.68(4.18$ to 14.09$)$ \\
p-trend & & $<0.001$ & $<0.001$ \\
\hline
\end{tabular}

Model 1; adjustment for age, sex.

Model 2; adjustment for age, sex, smoking, alcohol (daily; at least weekly; rarely; never), marital status (married; always single; separated; widowed), wealth quintile. 
criteria in the British Whitehall II study of civil servants. ${ }^{12}$ Slight differences are possibly due to variations in the criteria used for defining healthy ageing and also differences in follow-up time. For example, previous studies ${ }^{11} 12$ have used longer follow-up periods of 14-16 years, with younger samples at baseline. Thus, our sample may have already contained a high proportion of healthy survivors at baseline. Social function is included in the definition of healthy ageing although seldom used, thus this dimension of ageing should be considered in future studies.

Several previous studies, including the Cardiovascular Health Study, ${ }^{13}$ the Harvard Alumni Study, ${ }^{14}$ Whitehall II study ${ }^{12}$ and Nurses' Health Study ${ }^{11}$ have all observed strong associations with physical activity and exceptional survival. In contrast, other studies have not observed these associations. ${ }^{15}$ The present study is one of the first to assess associations between changes in activity and healthy aging. A reduction in physical activity may be one of the first indicators of the disease onset. However, in the present study participants who became physically active after baseline were more likely to be healthy than those who remained sedentary and those who became inactive. In a recent 11-year follow-up study of older Australian men, participants who met the physical activity recommendations at baseline and follow-up were most likely to be successful agers at follow-up. ${ }^{26}$ Several other cohort studies have demonstrated that an increase in physical activity in older age is protective against all-cause mortality. ${ }^{27} 28$ Although our assessment of physical activity change was crude, the results appear to suggest that maintaining or beginning any form of regular activity is beneficial. The mechanisms underlying these effects remain unclear. One key mechanism may involve inflammatory pathways. Regular physical activity is associated with sustained levels of lower inflammatory markers in older adults. ${ }^{29}$ In addition, low-grade inflammation has been linked to many of the components of healthy ageing, including chronic disease, ${ }^{30} 31$ depression, ${ }^{32}$ cognitive decline, ${ }^{33}$ sarcopenia and disability. ${ }^{34} 35$

Our study has some limitations. Chronic disease was based on self-report of physician diagnosis, though previous work has demonstrated the validity of this measure in ELSA. ${ }^{36}$ Self-reported physical activity was crudely assessed and, consistent with others, ${ }^{37}$ was modestly related to objective accelerometry measures. For this reason, and because self-reported physical activity in older adults has been shown to overestimate actual activity and underestimate its true effects on mortality in older adults, ${ }^{10}$ our study may have considerably underestimated the strength of associations between physical activity and healthy ageing. As in any observational study, residual confounding may explain our results. However, the effect estimates were a little attenuated after a range of multivariate adjustments. In a subsample with available clinical data we did also make adjustments for other clinical covariates such as body mass index, inflammatory markers, glucose metabolism and blood lipid levels, although these factors may be on the causal pathway linking physical activity with healthy ageing. The participants excluded from our analyses were less physically active and generally of lower social status, which could have introduced bias into the results, although the impact of resurvey non-response has been shown to have negligible effects in previous research. ${ }^{38}$ Despite these limitations, our study also has some notable strengths. These include the repeated serial collection of data enabling us to model changes in physical activity; the objective assessments of several healthy ageing outcomes; the use of a large national sample of community-dwelling men and women.
In summary, a sustained level of physical activity in older age is associated with improved overall health in participants surviving over an 8-year follow-up. Moreover, significant health benefits were even seen among participants who became physically active relatively late in life. This study supports public health initiatives designed to engage older adults in physical activity, even those who are of advanced age.

\section{What are the new findings?}

Sustained physical activity was prospectively associated with improved healthy ageing (absence of disease, freedom from disability, high cognitive and physical functioning, good mental health).

- Significant health benefits were even seen among participants who became physically active relatively late in life.

\section{How might it impact on clinical practice in the near} future?

The results support public health initiatives designed to engage older adults in physical activity.

Contributors $\mathrm{MH}$ had full access to the data, and takes responsibility for the integrity and accuracy of the results. All authors contributed to the concept and design of study, drafting and critical revision of the manuscript.

Funding The data were made available through the UK Data Archive. The English Longitudinal Study of Ageing (ELSA) was developed by a team of researchers based at University College London, the Institute of Fiscal Studies and the National Centre for Social Research. The funding is provided by the National Institute on Aging in theUSA(grants 2R01AG7644-01A1 and 2R01AG017644) and a consortium of UK government departments co-ordinated by the Office for National Statistics.

Competing interests $\mathrm{MH}$ is supported by the British Heart Foundation (RE/10/ 005/28296); KLL and SLB are supported by Chercheur boursier awards from the Fonds de recherché du Quebec — santé (FRQS) and New Investigator Awards from the Canadian Institutes of Health Research (CIHR).

\section{Patient consent Obtained.}

Ethics approval London Multi-Centre Research Ethics Committee.

Provenance and peer review Not commissioned; externally peer reviewed.

Data sharing statement The data were made available through the UK Data Archive.

Open Access This is an Open Access article distributed in accordance with the Creative Commons Attribution Non Commercial (CC BY-NC 3.0) license, which permits others to distribute, remix, adapt, build upon this work non-commercially, and license their derivative works on different terms, provided the original work is properly cited and the use is non-commercial. See: http://creativecommons.org/ licenses/by-nc/3.0/

\section{REFERENCES}

1 Landefeld CS, Winker MA, Chernof B. Clinical care in the aging centuryannouncing 'Care of the aging patient: from evidence to action'. JAMA 2009;302:2703-4.

2 Lagiewka K. European innovation partnership on active and healthy ageing: triggers of setting the headline target of 2 additional healthy life years at birth at EU average by 2020. Arch Public Health 2012;70:23.

3 Rowe JW, Kahn RL. Successful ageing. Gerontologist 1997;37:433-40.

4 Lee IM, Shiroma EJ, Lobelo F, et al. Effect of physical inactivity on major non-communicable diseases worldwide: an analysis of burden of disease and life expectancy. Lancet 2012;380:219-29. 
5 Paterson DH, Warburton DE. Physical activity and functional limitations in older adults: a systematic review related to Canada's Physical Activity Guidelines. Int J Behav Nutr Phys Activ 2010;7:38.

6 Hamer M, Chida Y. Physical activity and risk of neurodegenerative disease: a systematic review of prospective evidence. Psychol Med 2009:39:3-11.

7 Lautenschlager NT, Cox KL, Flicker L, et al. Effect of physical activity on cognitive function in older adults at risk for Alzheimer disease: a randomized trial. JAMA 2008;300:1027-37.

8 Villareal DT, Chode S, Parimi N, et al. Weight loss, exercise, or both and physical function in obese older adults. N Eng/ J Med 2011;364:1218-29.

9 Stessman J, Hammerman-Rozenberg R, Cohen A, et al. Physical activity, function and longevity among the very old. Arch Intern Med 2009;169:1476-83.

10 Manini TM, Everhart JE, Patel KV, et al. Daily activity energy expenditure and mortality among older adults. JAMA 2006:296:171-9.

11 Sun Q, Townsend MK, Okereke Ol, et al. Physical activity at midlife in relation to successful survival in women at age 70 years or older. Arch Intern Med 2010;170:194-201.

12 Sabia S, Singh-Manoux A, Hagger-Johnson G, et al. Influence of individual and combined healthy behaviours on successful aging. CMAJ 2012;184:1985-92.

13 Newman AB, Arnold AM, Naydeck BL, et al.; Cardiovascular Health Study Research Group. 'Successful aging': effect of subclinical cardiovascular disease. Arch Intern Med 2003;163:2315-22.

14 Vaillant GE, Mukamal K. Successful ageing. Am J Psychiatry 2001;158:839-47.

15 Willcox $B J$, He $Q$, Chen $R$, et al. Midlife risk factors and healthy survival in men. JAMA 2006;296:2343-50.

16 ELSA user guide and documentation. UK Data Archive. http://www.data-archive.ac. uk/findingData/snDescription.asp?sn=5050 (accessed 21 Aug 2008).

17 Hamer M, Molloy GJ, de Oliveira C, et al. Leisure time physical activity, risk of depressive symptoms, and inflammatory mediators: the English Longitudinal Study of Ageing. Psychoneuroendocrinology 2009;34:1050-5.

18 Wilson RS, Leurgans SE, Boyle PA, et al. Neurodegenerative basis of age-related cognitive decline. Neurology 2010;75:1070-8.

19 Steffick DE. Documentation of affective functioning measures in the Health and Retirement Study (HRS/AHEAD Documentation. Report DR-005). Ann Arbor, MI: Survey Research Center, University of Michigan, US. 2000. http://hrsonline.isr.umich. edu/docs/userg/dr-005.pdf

20 Irwin M. Screening for depression in the older adult. Arch Intern Med 1999;159:1701-4

21 Van de Velde S, Levecque K, Bracke P. Measurement equivalence of the CES-D 8 in the general population in Belgium: a gender perspective. Arch Public Health 2009;67:15-29.

22 Katz S, Downs TD, Cash HR, et al. Progress in development of the index of ADL. Gerontologist 1970;10:20-30.

23 Lawton MP, Brody EM. Assessment of older people: self-maintaining and instrumental activities of daily living. Gerontologist 1969;9:179-86.
24 Studenski S, Perera $\mathrm{S}$, Patel $\mathrm{K}$, et al. Gait speed and survival in older adults. JAMA 2011;305:50-8

25 Banks JA, Karlsen S, Oldfield Z. Socio-economic position. In: Marmot M, Banks JA, Blundell R, Lessof C, Nazroo J.eds Health, wealth and lifestyles of the older population in England: the 2002 English Longitudinal Study of Ageing. London: Institute of Fiscal Studies, 2003:15.

26 Almeida OP, Khan KM, Hankey GJ, et al. 150 minutes of vigorous physical activity per week predicts survival and successful ageing: a population based 11-year longitudinal study of 12201 older Australian men. Br J Sports Med 2013 Sep 3. doi:10.1136/bjsports-2013-092814

27 Wannamethee SG, Shaper AG, Walker M. Changes in physical activity, mortality, and incidence of coronary heart disease in older men. Lancet 1998;351:1603-8.

28 Byberg L, Melhus H, Gedeborg R, et al. Total mortality after changes in leisure time physical activity in 50 year old men: 35 year follow-up of population based cohort. BMJ 2009;338:b688.

29 Hamer M, Sabia S, Batty GD, et al. Physical activity and inflammatory markers over 10 years: follow-up in men and women from the Whitehall II cohort study. Circulation 2012;126:928-33.

30 Vasto S, Carruba G, Lio D, et al. Inflammation, ageing and cancer. Mech Ageing Dev 2009:130:40-5.

31 Hingorani AD, Casas JP; Interleukin-6 Receptor Mendelian Randomisation Analysis (IL6R MR) Consortium. The interleukin-6 receptor as a target for prevention of coronary heart disease: a Mendelian randomisation analysis. Lancet 2012;379:1214-24.

32 Dantzer R, O'Connor JC, Freund GG, et al. From inflammation to sickness and depression: when the immune system subjugates the brain. Nat Rev Neurosci 2008;9:46-56.

33 Rafnsson SB, Deary IJ, Smith FB, et al. Cognitive decline and markers of inflammation and hemostasis: the Edinburgh Artery Study. J Am Geriatr Soc 2007;55:700-7

34 Hamer M, Molloy GJ. Association of C-reactive protein and muscle strength in the English Longitudinal Study of Ageing. Age (Dordr) 2009;31:171-7.

35 Brinkley TE, Leng $\mathrm{X}$, Miller ME, et al. Chronic inflammation is associated with low physical function in older adults across multiple comorbidities. J Gerontol A Biol Sci Med Sci 2009:64:455-61.

36 Pierce MB, Zaninotto $P$, Steel $N$, et al. Undiagnosed diabetes-data from the English longitudinal study of ageing. Diabet Med 2009;26:679-85.

37 Hamer M, Kivimaki M, Steptoe A. Longitudinal patterns in physical activity and sedentary behaviour from mid-life to early old age: a sub-study of the Whitehall II cohort. J Epidemiol Community Health 2012:66:1110-15.

38 Batty GD, Gale CR. Impact of resurvey non-response on the associations between baseline risk factors and cardiovascular disease mortality: prospective cohort study. J Epidemiol Community Health 2009;63:952-5. 